\title{
COLETA SELETIVA E RECICLAGEM COMO INSTRUMENTOS PARA CONSERVAÇÃO AMBIENTAL: UM ESTUDO DE CASO EM UBERLÂNDIA, MG
}

\section{Separate collection and recycling as instruments to environmental conservation: a case study in Uberlândia, MG, Brazil}

\author{
Erika Hisatugo \\ Mestre em Ecologia e Conservação de Recursos Naturais pela Universidade Federal de Uberlândia \\ kkiikkaa@yahoo.com \\ Oswaldo Marçal Júnior \\ Professor adjunto da Universidade Federal de Uberlândia \\ marcaljr@ufu.br
}

Artigo recebido para publicação em 26/03/2007 e aceito para publicação em 08/08/2007

RESUMO: Um dos maiores problemas dos centros urbanos é a destinação final do lixo, situação agravada pelo modelo capitalista. A coleta seletiva e a reciclagem de materiais estão entre as principais soluções para esse problema. Este estudo teve como objetivo determinar a quantidade de materiais coletada por uma das empresas de coleta seletiva da cidade de Uberlândia (MG) e avaliar os ganhos ambientais potenciais advindos desse processo. No período 2001/2004, as atividades da empresa foram acompanhadas pela pesquisadora, que também teve acesso aos registros referentes à separação, classificação e pesagem dos materiais. Foram realizados cálculos de economias potenciais de energia e recursos naturais. No total, foram coletadas 4.727,74 t de materiais recicláveis. A média de alumínio desviado do aterro foi de 8,22 t./ano, o que proporcionaria uma economia de bauxita de 41,1 t. O peso médio de papel coletado foi de 804,26 t./ano, possibilitando uma economia de água de 19.571,63 mil litros anuais. O peso médio de plástico foi de 369,51 t./ano. Lembramos que a reciclagem de plásticos proporciona economia de um importante recurso não-renovável: o petróleo. Os resultados indicam que a coleta seletiva de materiais e sua reciclagem podem oferecer ganhos econômicos e ambientais significativos para a cidade de Uberlândia.

Palavras-chave: lixo, reciclagem, coleta seletiva, conservação ambiental.

ABSTRACT: One of the biggest problems of urban centers is the final disposal of waste, the capitalist system makes this situation worse. The separate collection and material recycling are among the principal solutions to this problem. This study aims to determine the quantity of collected materials from a separate collection company from the city of Uberlândia (MG) and to evaluate the environmental gains from this process. In the period 2001/2004, the activities carried out by the company were accompanied by the researcher, who also had access to the data registers regarding to the separation, classification and weight of recyclable materials. This data were used to calculate the potential savings in terms of energy and natural resources. In total, there were 4.727,74 t. of recyclable materials collected. The mean weight of aluminum deviated from 
the landfill was 8,22 t/year, this may provide a bauxite saving of 41,1 t. The mean weight of paper was 804,26 t/year, allowing a water saving of 19.571,63 thousand of liters. The mean weight of plastic was 369,51 t/year. We remind that plastics recycling provides saving of an important non-renewable resource: oil. The results indicate that the separate collection and materials recycling may offer significant economics and environmental gains to the city of Uberlândia.

Keywords: waste, recycling, separate collection, environmental conservation.

\section{INTRODUÇÃO}

No passado, a produção de lixo pela população não causava o impacto sobre o meio ambiente que pode ser visto hoje, uma vez que a maioria dos resíduos produzidos era de natureza orgânica e, portanto, mais fácil de ser degradada. Além disso, restos de comida, frutas e legumes eram utilizados na alimentação de animais domésticos, o que também contribuía para diminuir o volume dos resíduos sólidos (Cavalcante, 2002).

A Revolução Industrial, iniciada na Inglaterra em 1779, desencadeou o processo de urbanização (Dias, 2002), mudando significativamente a vida das pessoas. O elevado índice de urbanização e o sistema capitalista de produção são características marcantes da sociedade moderna. Nessa perspectiva, o consumismo se incorporou ao modo de pensar e agir das pessoas. Segundo Dias (2002), os centros urbanos são pontos de indução de alterações ambientais, ocupando apenas $2 \%$ da superfície terrestre; porém, consumindo $75 \%$ dos seus recursos. Uma situação que é amplamente estimulada pela mídia.

O consumo é estimulado pela mídia - especialista em criar "necessidades desnecessárias" -, tornando as pessoas amarguradas ao desejarem ardentemente algo que não podem comprar, sem o qual viviam muito bem, antes de conhecerem as sofisticadas $e$ ilusórias pu-blicidades. O que se vende não é apenas um produto, mas um estilo de vida (Dias, 2002, p.116)
A utilização excessiva de embalagens na comercialização de produtos, tem sido outra característica do modo industrial vigente. Embalagens múltiplas são utilizadas para proteção dos produtos, distribuição, e promoção de vendas, conferindo praticidade e atratividade, mas ao mesmo tempo aumentando a produção de resíduos sólidos (Gradvohl, 2001).

Na agitação do dia-a-dia vivido pela maioria das pessoas que vivem nas grandes cidades, há uma grande valorização dos produtos práticos e descartáveis, o que aumenta ainda mais o volume do lixo produzido. Produtos duradouros e reutilizáveis, considerados de boa qualidade até algum tempo atrás, perderam terreno para os descartáveis (Gradvohl, 2001). Nas palavras de Rodrigues (1998, p. 23):

Um grande problema, da intensificação da produção/destrutiva, senão o maior, está no que se convencionou chamar de problemática ambiental, na criação de novas necessidades que não satisfazem necessidades humanas enriquecedoras, mas apenas correspondem a modos de vida da sociedade do descartável. E, na sociedade do descartável, o tempo e o espaço são tidos como separados, produzem-se cada vez mais e mais mercadorias - que duram cada vez menos - , e utiliza-se de forma intensiva o espaço para produzir mais.

Cerca de 70\% da população brasileira, mais de 100 milhões de pessoas, vivem em centros urbanos, sendo que $40 \%$ desse total não estão incluídos na chamada sociedade de consumo (Gradvohl, 2001). Esses números mostram a realidade do país, no qual a maior parte da 
população é de baixa renda e não tem acesso aos mesmos itens de consumo utilizados pela minoria. Desse modo, a parcela da população que detêm um maior poder aquisitivo é a principal responsável pelas mazelas originadas do consumismo, sobretudo aquelas produzidas pelo uso desenfreado de produtos descartáveis.

No Brasil, são produzidas cerca de 47.450 mil toneladas de lixo por ano (Bley Jr, 2001). Nos últimos anos, tem sido verificado um aumento desse volume superior a $10 \%$ ao ano, chegando a $40 \%$ em Salvador e 22\% no Rio de Janeiro e Curitiba (Cozetti, 2001). A Pesquisa Nacional de Saneamento Básico 2000 revelou uma melhoria na situação da destinação final do lixo no país. Este estudo verificou que em $2000,47,1 \%$ do lixo produzido era destinado a aterros sanitários, 22,3\% a aterros controlados e apenas 30,5 \% a lixões (Instituto Brasileiro de Geografia e Estatística - IBGE, 2002).

Em relação à problemática do lixo no Brasil, a falta de espaço para a sua disposição final é outro fator agravante, que está relacionado com a rápida saturação dos aterros sanitários. Há várias maneiras de diminuir o volume de lixo destinado aos aterros como incineração, digestão anaeróbia, compostagem, coleta seletiva ou separação pós-coleta. A reciclagem de materiais usados constitui-se em uma das principais soluções (Bianchini, 2001). Apesar de ser um processo caro, apresenta muitos benefícios, que são destacados por Grippi (2001, p. 78):

melhoria das condições ambientais e sanitárias dentro do município, a diminuição no volume de lixo que necessita ser aterrado, o aumento da vida útil do aterro, a economia de energia, a economia de matéria-prima virgem. Os benefícios sociais, geração de empregos diretos e indiretos, geração de renda com a venda do composto orgânico e de materiais recicláveis, o despertar do sentimento de cidadania.

A reciclagem já é uma realidade no país, atingindo índices invejáveis para alguns produtos, como latas de alumínio 95,7\% (Compromisso Empre- sarial para Reciclagem - CEMPRE, 2006c); papel ondulado 79\% (CEMPRE, 2006b); vidro 46\% (CEMPRE, 2006d); garrafas PET 48\% (CEMPRE, 2006e); papel de escritório 33\% (CEMPRE, 2006a).

Um processo de extrema importância para o sucesso da reciclagem é a coleta seletiva de lixo, que compreende a separação e coleta de materiais recicláveis na fonte geradora (Vilhena \&D’Almeida, 2000). Segundo Neiva (2001), o principal problema enfrentado para o crescimento da reciclagem dos diversos tipos de materiais é a inexistência ou a ineficiência de programas de coleta seletiva. Esses programas devem propiciar a separação do lixo em papel, plástico, vidro, metal e matéria orgânica, assegurando melhor qualidade desses materiais e facilitando a sua reciclagem. Para o seu sucesso, a separação do lixo em cada categoria deve começar nas próprias residências com cada um exercendo seu papel de cidadão.

O avanço da tecnologia tem sido acompanhado de intensa degradação ambiental, em todo o mundo (Vilhena, 1996). A Educação Ambiental - EA tem papel muito importante na solução dessa problemática, especialmente na questão do lixo, uma vez que as pessoas precisam estar sensíveis ao problema para se dispor a ajudar. Vilhena (1996) afirma que a educação ambiental é a mola propulsora de qualquer iniciativa de preservação ambiental, que tenha o cidadão como personagem principal. Através da EA é exposto o problema do lixo, informes sobre a coleta seletiva, como separar o lixo e a importância da cooperação de cada um, na tentativa de sensibilizar as pessoas.

Contudo, o maior problema da gestão da limpeza pública no Brasil é de natureza estrutural. Seria necessário aplicar o princípio poluidor-pagador para uma gestão adequada em que a fonte geradora pagaria pelo volume de lixo gerado. Assim, seriam estimuladas a redução da quantidade de lixo produzido e a separação dos materiais recicláveis no interior das residências para reduzir o volume de lixo destinado à coleta geral. Outro fator importante seria a necessidade de acabar com a tributação em cima dos 
reciclados, pois ela onera e desestimula a reciclagem, sendo que as taxas tributárias dos materiais que são reutilizados já foram pagas na primeira cadeia de produção. No Brasil, o lixo orgânico constitui 55\% do peso do lixo urbano e por isso também deveria ser separado dos rejeitos para uma gestão adequada por meio da compostagem (Bley Jr., 2001). O setor de alimentos consome mais da metade da produção de embalagens, sendo o maior responsável pelo lixo urbano reciclável (Gradvohl, 2001).

Nesse contexto, realizamos o presente trabalho, com os seguintes objetivos:

- quantificar os materiais coletados por uma das empresas de comercialização de recicláveis de Uberlândia (MG), no período de 2001 a 2004;

- avaliar os ganhos ambientais potenciais advindos desse processo de coleta seletiva;

\section{MATERIAIS E MÉTODOS}

\section{1. Área de Estudo}

A cidade de Uberlândia está localizada no Triângulo Mineiro/Alto Paranaíba, estado de Minas Gerais. Essa região situa-se dentro do Bioma Cerrado, que foi incluído recentemente na lista dos 25 "hot spots” (áreas críticas para conservação no mundo), definidas com base na existência de espécies endêmicas e no grau de ameaça ambiental (Conservation International do Brasil, 1999; Drummond, 2005). O Cerrado ocupava a maior parte dos chapadões do município de Uberlândia, mas encontra-se restrito a pequenas reservas isoladas (Araújo et al., 1997).

Em 2006, sua população era de cerca de 600.368 habitantes, a maioria dos quais concentrados na zona urbana (IBGE, 2007). Segundo dados da Limpel Atividades Urbanas Ltda (empresa responsável pela coleta convencional de lixo), são coletadas, em média, 350 toneladas de lixo por dia na cidade e todo este volume é destinado ao aterro sanitário.
A cidade não possui coleta seletiva, sendo esse serviço realizado por catadores independentes e por empresas que comercializam materiais recicláveis. Desde 2002, foi criada uma cooperativa, a Associação dos Catadores de Papelão e Materiais Recicláveis de Uberlândia - ASCAPEL, que passou a congregar vários catadores locais. Todos os materiais coletados são vendidos a ASCAPEL ou às empresas privadas do ramo. Em 2001, apenas duas dessas empresas estavam estabelecidas em Uberlândia. Em 2002, outras doze empresas passaram a explorar esse ramo de atividade na cidade, mas nem todas permaneceram abertas até o final desta pesquisa, em 2004.

\subsection{Metodologia}

No período de fevereiro de 2001 a dezembro de 2004, foram coletados dados mensais referentes à coleta seletiva de materiais recicláveis, oriundos da RECICLO, uma das duas empresas pioneiras no setor em Uberlândia. As atividades desenvolvidas pela empresa foram acompanhadas pela pesquisadora, que também teve acesso irrestrito aos arquivos e registros de dados referentes à separação, classificação e pesagem dos materiais recicláveis (pesquisa documental).

Para pesagem dos materiais, realizada pelos funcionários, foi utilizada uma balança industrial, com capacidade de $999 \mathrm{Kg}$.

Os materiais recicláveis foram classificados pela autora, sendo separados nas seguintes categorias: 1. papel, inclui-se papel branco, jornal, listagem, kraft, misto, papelão ondulado, sucatas de papelão, tipografia e revistas; 2. alumínio, foi representado por latas de alumínio, alumínio mole e alumínio duro; 3. plásticos, incluindo plásticos recicláveis, como Polietileno Tereftalato - PET, Polietileno de Alta Densidade - PEAD, Policloreto de Vinila - PVC, Polietileno de Baixa Densidade - PEBD, Polipropileno PP, Poliestireno - PS, ráfia, plástico mole, plástico duro, tampas e sucatas de plásticos.

Os cálculos de economia energética e de 
recursos naturais (água e matéria-prima) foram realizados de acordo com a Tabela 1 . Trabalhou-se com economias potenciais, uma vez que o processo de reciclagem dos mesmos não foi acompanhado.

Tabela 1. Indicadores da reciclagem do alumínio, papel e plástico

\begin{tabular}{|l|l|}
\hline \multicolumn{2}{|c|}{ Indicadores da reciclagem de alumínio } \\
\hline Economia de bauxita decorrente da reciclagem & 5 toneladas de bauxita por tonelada de alumínio \\
\hline Economia de energia elétrica na produção através da reciclagem & $16,9 \mathrm{mil} \mathrm{kWh} / \mathrm{t}$ \\
\hline \multicolumn{2}{|c|}{ Indicadores da reciclagem de papel } \\
\hline Economia de energia elétrica através da reciclagem & $3,51 \mathrm{mil} \mathrm{kWh} / \mathrm{t}$ \\
\hline Economia de matéria-prima & 20 árvores por tonelada \\
\hline Economia de água & 29.202 litros/t \\
\hline Produção de papel reciclado & $1,2 \mathrm{t}$ de papel usado produz uma tonelada de papel reciclado \\
\hline & Indicadores da reciclagem de plástico \\
\hline Economia de energia elétrica obtida com a reciclagem & $5,3 \mathrm{mil} \mathrm{kWh} / \mathrm{t}$ \\
\hline Economia de petróleo & $500 \mathrm{~kg} / \mathrm{t}$ \\
\hline
\end{tabular}

\section{RESULTADOS E DISCUSSÃO}

O total de materiais recicláveis coletado ao longo do período investigado foi de 4.727,74 t, com média de 1.181,94 t por ano. A menor quantidade foi coletada em 2001 e a maior em 2003 (521,51 t e $2.140,7 \mathrm{t}$, respectivamente). Papelão ondulado foi o material com maior peso coletado, com 2.444,26 t no período; seguido por PEBD (643,05 t) e PET (617,72 t). Sucatas de plástico, por sua vez, apresentaram o menor peso coletado, totalizando $0,59 \mathrm{t}$ no período (Quadro 1).

Materiais recicláveis compõem, em média, $35 \%$ do lixo nas cidades brasileiras, percentual que deveria ser retornado ao mercado consumidor via reciclagem, diminuindo os impactos ambientais causados pelo grande volume de lixo descartado no meio (Gradvohl, 2001). Porém, esses reciclados devem encontrar mercado consumidor; caso contrário, voltarão aos aterros.

Os resultados gerais mostram que houve um crescimento no peso de materiais coletados, no período de 2001 a 2003, sendo registrada uma queda acentuada no último ano investigado. Isso se deveu, em grande parte, ao acirramento da concorrência de mer- cado, que culminou com o fechamento da empresa fornecedora dos dados para análise. Segundo informações da própria administração da empresa pesquisada, os altos impostos cobrados pelo governo para o funcionamento da mesma também teriam colaborado para o seu fechamento, já que outras empresas desse ramo de atividade não pagavam os impostos devidos, podendo, assim, oferecer um melhor preço na compra dos recicláveis, numa clara forma de concorrência desleal.

O maior peso registrado na coleta de papéis, em relação aos outros materiais investigados, pode ser explicada pela diferença de peso entre eles, sobretudo porque o principal tipo de papel coletado foi papelão ondulado. Já o fato de alumínio ter apresentado o menor peso total entre os materiais coletados era esperado, em função de sua natureza. Além disso, observou-se um decréscimo contínuo ao longo dos anos pesquisados no peso coletado desse material, o que acreditamos ter sido uma conseqüência do aumento na concorrência pela comercialização de recicláveis, advinda da abertura de novas empresas do ramo, a partir de 2002. Devemos lembrar que o alumínio tem os melhores preços no mercado de recicláveis, o que gera essa maior procura e concorrência. 


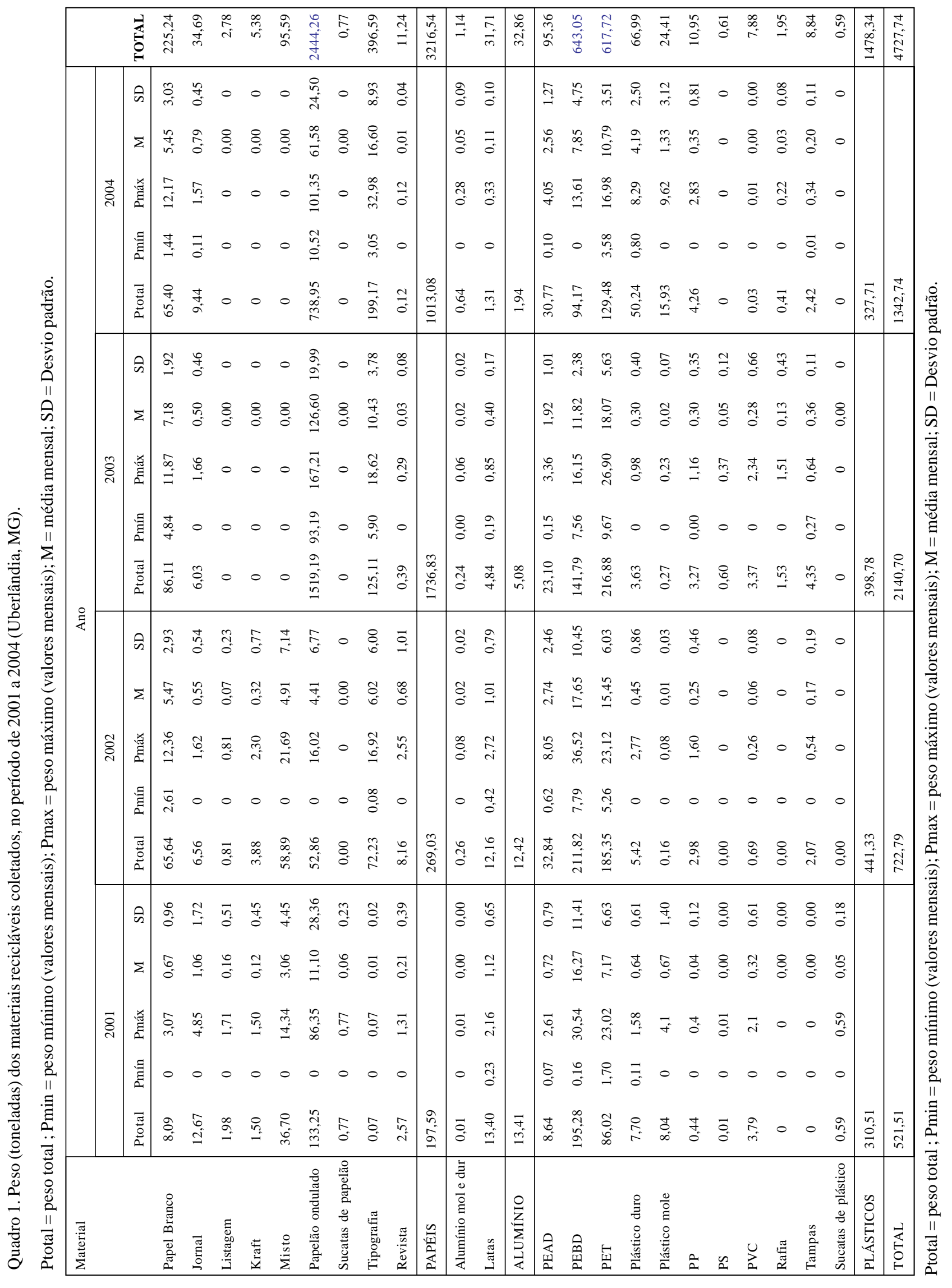

Sociedade \& Natureza, Uberlândia, 19 (2): 205-216, dez. 2007 
É importante ressaltar que os dados utilizados no presente estudo representam apenas uma parcela do volume total de materiais recicláveis coletados em Uberlândia, ou seja, são subestimativas do impacto potencial positivo que a coleta seletiva e a reciclagem produzem na cidade como um todo.

\section{Alumínio}

A média anual da quantidade de alumínio desviado do aterro foi de 8,22 $\mathrm{t}$, tendo sido atingido o maior peso (13,41 t), em 2001. Em relação às latas de alumínio, foram coletadas 2.219.700 latas
(1 Kg = 70 latas) durante os quatro anos estudados. Esse desvio foi muito importante, entre outras razões, pelo fato das latas de alumínio demorarem de 100 a 500 anos para serem degradadas naturalmente (Grippi, 2001).

A economia potencial média anual de bauxita, matéria-prima do alumínio, que poderia ser obtida a partir da reciclagem é de 41,1 t (Figura 1). Trata-se de um resultado significativo, se considerarmos que a bauxita, segundo Calderoni (2003), é um recurso não-renovável cujas reservas existentes têm duração estimada em cerca de 50 a 100 anos.

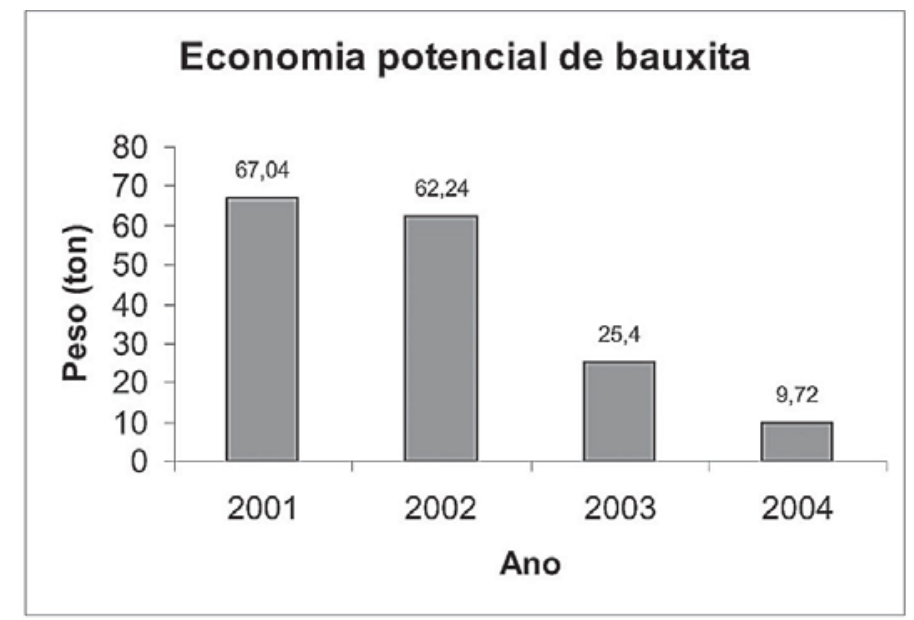

Figura 1. Economia de bauxita que poderia ser obtida por meio da reciclagem de alumínio, no período de 2001 a 2004, em Uberlândia (MG).

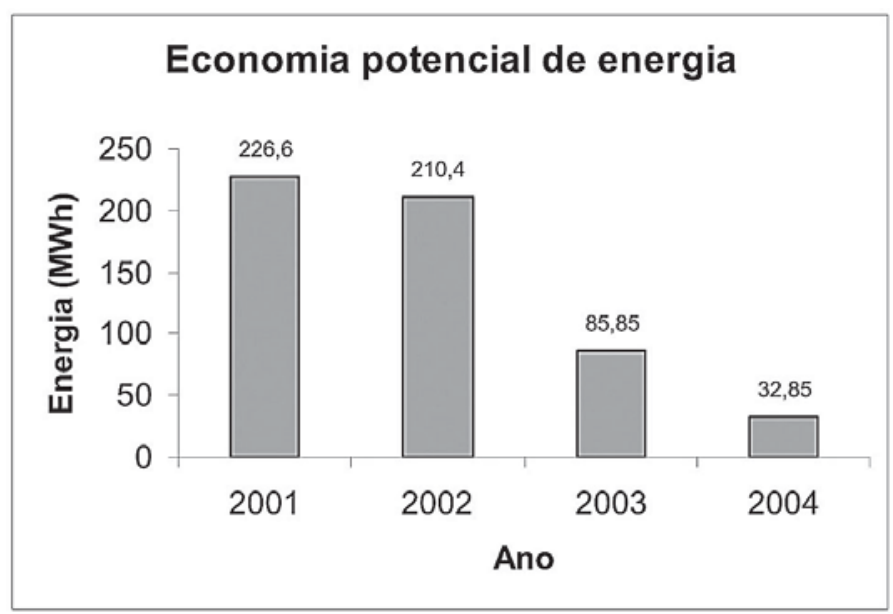

Figura 2. Economia de energia que poderia ser alcançada por meio da reciclagem de alumínio, no período de 2001 a 2004, em Uberlândia (MG). 
Em relação à energia, a economia potencial média anual verificada no presente estudo é da ordem de 138,93 MWh (Figura 2). A reciclagem de uma única lata de alumínio economiza energia elétrica equivalente ao consumo de um aparelho de TV durante três horas. Convém destacar que o Brasil é o país que mais recicla latas de alumínio no mundo, tendo atingido um índice de reciclagem de 95,7\%, em 2004 (CEMPRE, 2006c).

É importante ressaltar que a lata de alumínio pode ser reciclada infinitas vezes, sem que haja perda de suas propriedades. Essa reciclagem proporciona uma redução da poluição da água de $97 \%$ e do ar de 95\% (Calderoni, 2003).

Levantamento realizado pelo Centro de Tecnologia de Embalagem - CETEA, comparando a produção de uma tonelada de latas de alumínio (a partir de latas recicladas e de alumínio primário), mostrou que, com a reciclagem, houve uma redução de aproximadamente $65 \%$ nas emissões de metano e em torno de 80\% de dióxido de carbono (CEMPRE,
2005). Ayres (1997) realizou um estudo sobre reciclagem de metais, mostrando que cada tonelada de metal que é reutilizado, remanufaturado ou reciclado repõe uma tonelada que teria que ser processado, com custos de energia e materiais necessários para essas atividades. Assim, cada tonelada de ferro reciclado economiza 12,5 t de sobrecarga (carvão e mineração de ferro), 2,8 $\mathrm{t}$ de minério de ferro, 0,8 $\mathrm{t}$ de carvão (exclusivamente usado como combustível). Também elimina pelo menos uma tonelada de $\mathrm{CO} 2$, que seria emitida para $o$ ar.

\section{Papel}

O peso médio anual de papel reciclável desviado do aterro foi de 804,26 t. Esse montante possibilita uma produção média de 670,22 $\mathrm{t}$ de papel reciclado. Em 2003, verificou-se a maior quantidade de papel reciclável (1.736,82 t) (Figura 3). Entre os ganhos ambientais que poderiam ser obtidos com a reciclagem do papel encontram-se a economia de água, com média de 19.571,63 mil litros anuais e a economia de energia com média de 2.352,46 MWh.

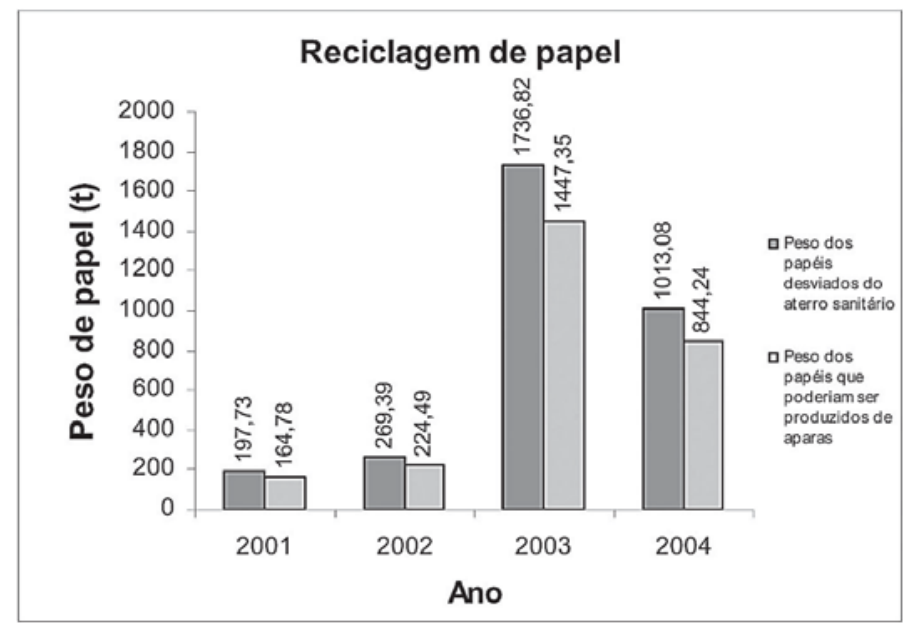

Figura 3. Quantidade de papel desviado do aterro sanitário de Uberlândia (MG) por meio da coleta seletiva e montante de papel reciclado que poderia ser produzido de aparas, no período de 2001 a 2004, em Uberlândia (MG).

No final de 1998, as empresas do setor papeleiro do Brasil ocupavam uma área de 1,5 milhão de hectares de reflorestamentos, sendo $65 \%$ de eucalipto, $31 \%$ de pinus e $4 \%$ de outras espécies
(D’Almeida \& Neves, 2000). Portanto, outro ganho potencial importante é a economia média de matériaprima que seria de 13.404,3 árvores por ano (Figura 4). 


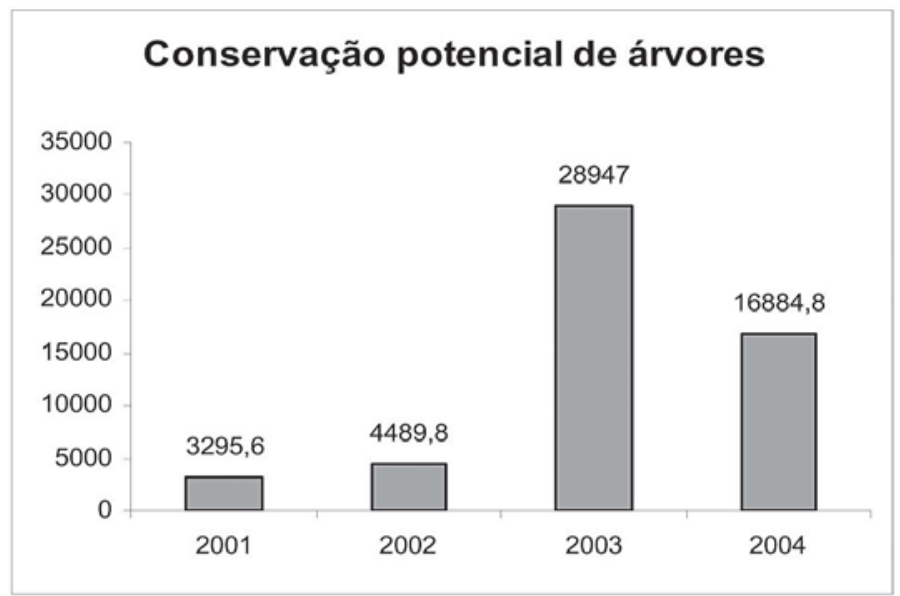

Figura 4. Número de árvores que poderiam ser preservadas com a reciclagem de papel, no período de 2001 a 2004, em Uberlândia (MG).

Os resultados obtidos indicam a importância da reciclagem do papel para conservação, pois além de possibilitar a redução no ritmo de extração de árvores, pode proporcionar uma diminuição de áreas destinadas à silvicultura, que poderiam ser utilizadas para fins de conservação de espécies nativas.

\section{Plástico}

O peso médio anual de plástico desviado do aterro foi de 369,51 t. Esse desvio foi muito significativo, pois materiais plásticos são muito leves, perfazendo um grande volume, além de permanecerem muito tempo no meio (por exemplo, copos de plástico demoram de 200 a 450 anos para biodegradar) (Grippi, 2001). A economia potencial média de energia que poderia ser obtida com a reciclagem dos materiais plásticos coletados é de 1.958,40 MWh por ano.

Como materiais plásticos são derivados do petróleo, a reciclagem dos mesmos poderia proporcionar uma economia média anual de 184,75 t de petróleo no período deste estudo (Figura 5). Essa economia é muito importante, pois o petróleo é um recurso não-renovável. Em um estudo realizado pelo CETEA, a reciclagem de PET baixou as emissões de dióxido de carbono em $25 \%$ e de metano em $18 \%$ (CEMPRE, 2005).

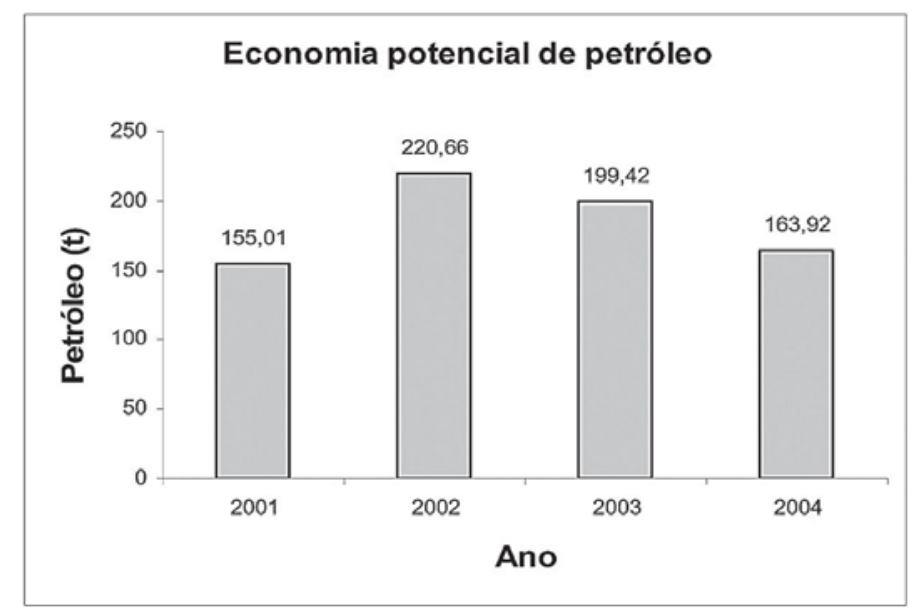

Figura 5. Economia de petróleo que poderia ser obtida com a reciclagem de materiais plásticos, no período de 2001 a 2004, em Uberlândia (MG). 
As economias potenciais de água e energia, que poderiam ser alcançadas com a reciclagem de alumínio, papel e plástico, são de extrema importância ambiental. É bom lembrar que apenas 0,35\% da água de todo o planeta está disponível para uso, dentro deste contexto, sessenta nações encontram-se em conflito por causa da água (Dias, 2004).

Oliveira (2001) realizou um estudo que analisou os custos do sistema de coleta seletiva e do sistema de coleta tradicional, destacando o potencial brasileiro para gerar energia elétrica a partir de resíduos sólidos. Nessa pesquisa, o referido autor mostrou que a economia de energia que poderia ser alcançada, no Brasil, por meio da produção industrial usando recicláveis, seria da ordem de 27,2 TWh. $\mathrm{Na}$ época, o consumo anual era de aproximadamente $300 \mathrm{TWh}$, portanto essa economia representaria 9\% da oferta de energia elétrica.

A degradação antrópica do meio ambiente atingiu um estágio alarmante. Esse quadro aumentou a discussão sobre uma mudança na maneira do homem se relacionar com a natureza. Neste contexto, o sistema de gestão dos resíduos sólidos e o sistema de energia são duas áreas de grande importância (Holmgren \&Henning, 2004), que tem a reciclagem como ponto comum. Para um sistema se autosustentar os recursos renováveis devem ser usados numa velocidade que permita sua regeneração; os recursos não-renováveis não podem ser utilizados numa taxa mais rápida que seu tempo de substituição e a poluição não deve ser gerada numa velocidade maior que o tempo necessário para sua absorção pelo meio (Leão et al., 2001). Nesse aspecto, a coleta seletiva de materiais e a sua reciclagem são de extrema importância, como foi demonstrado nesse estudo.

\section{CONCLUSÕES}

O presente estudo mostra que a empresa RECICLO coletou um volume significativo de materiais recicláveis em Uberlândia, no período de 2001 a 2004, com destaque para papéis e plásticos.

A reciclagem de papel coletada propor- cionaria a maior economia de energia entre todas as categorias estudadas, com média anual de 2.352,46 MWh. Além disso, a economia de água seria extremamente importante, totalizando 78.286.500 litros de água durante os anos estudados.

Os resultados obtidos demonstram o grande potencial da reciclagem como instrumento de preservação ambiental. Neste sentido, a implantação gradativa de programas de coleta seletiva nos bairros do município de Uberlândia, por meio da formalização de parcerias público-privadas, é fundamental para ampliação da oferta de recicláveis e conseqüente redução dos custos operacionais. O envolvimento da administração municipal é de suma importância para a sustentabilidade do setor, trazendo ganhos significativos em termos ambientais, sociais e econômicos.

\section{AGRADECIMENTOS}

À Fundação de Coordenação e Aperfeiçoamento Pessoal de Nível Superior, ao Programa de Pós-graduação em Ecologia e Conservação de Recursos Naturais da Universidade Federal de Uberlândia e à empresa Reciclo.

\section{REFERÊNCIAS BIBLIOGRÁFICAS}

ARAÚJO, G. M. et al.1997. Estrutura comunitária de vinte áreas de cerrados residuais no município de Uberlândia, MG. Daphne, Belo Horizonte, v. 7, n. 2, p. 7-14, abr. 1997.

AYRES, R. U. Metals recycling: economic and environmental implications. Resources Conservation and Recycling, Amsterdã, v. 21, n. 3, p. 145-173, nov. 1997. Disponível em: <http://www.science direct.com/science> Acesso em: 17 dez. 2005.

BIANCHINI, T. Coleta seletiva é a saída. Ecologia e Desenvolvimento, Rio de Janeiro, a. 11, n. 96, p. 20, set. 2001.

BLEY JR, C. Lixo no Brasil e no Mundo. Seminário Nacional de Resíduos Sólidos e Limpeza Urbana, São Paulo, set. 2001. 
CALDERONI, S. 2003. Os bilhões perdidos no lixo. 4. ed. São Paulo: Humanitas Editora/FFLCH/ USP, 2003. 346 p.

CAVALCANTE, M. D. L. A destinação final de resíduos. Banas Qualidade, a. 12, n. 126, p. 104106, nov. 2002.

CEMPRE, Compromisso Empresarial Para a Reciclagem. CEMPRE informa: Reciclagem ajuda a controlar a temperatura do planeta. $n$. 80 , mar./ abr. 2005. Disponível em < http://www.cempre.org. br/cempre_informa.php?lnk=ci_2005-0304.php >. Acesso em: 27 fev. 2007.

CEMPRE. Ficha Técnica: Papel de escritório. 2006a. Disponível em <http://www.cempre.org.br/ fichas_tecnicas.php?lnk=ft_papel_escritorio.php $>$. Acesso em: 27 fev. 2007.

CEMPRE. Ficha Técnica: Papel ondulado. 2006b. Disponível em: < http://www.cempre.org.br/fichas_ tecnicas.php?lnk=ft_papel_ondulado.php $>$. Acesso em: 27 fev. 2007.

CEMPRE. Ficha Técnica: Latas de alumínio. 2006c. Disponível em: <http://www.cempre.org.br/ fichas_tecnicas.php?lnk=ft_latas_aluminio.php $>$. Acesso em: 27 fev. 2007.

CEMPRE. Ficha Técnica: Vidro. 2006d. Disponível em: <http://www.cempre.org.br/fichas_tecnicas.php? lnk=ft_vidro.php $>$. Acesso em: 27 fev. 2007.

CEMPRE. Ficha Técnica: PET. 2006e. Disponível em: <http://www.cempre.org.br/fichas_tecnicas.php? lnk=ft_pet.php >. Acesso em: 27 fev. 2007.

\section{CONSERVATION INTERNATIONAL DO BRASIL} (ed.). Ações prioritárias para conservação da biodiversidade do cerrado e pantanal, Brasília, DF, 1999. 26 p.

COZETTI, N. Lixo: marca incômoda da modernidade. Ecologia e Desenvolvimento, Rio de Janeiro, a. 11, n. 96, p. 10-17, set. 2001.
D’ALMEIDA, M. L. O.; NEVES, J. M. Processamento do lixo: reciclagem de papel. In: D'Almeida, M. L. O.; VILHENA, A. (coordenadores). Lixo municipal: manual de gerenciamento integrado. São Paulo: IPT/CEMPRE, 2000. p. 127-141.

DIAS, G. F. Ecopercepção: um resumo didático dos desafios socioambientais. São Paulo: Editora Gaia, 2004. $63 \mathrm{p}$.

DIAS, G.F. Pegada ecológica e sustentabilidade humana. São Paulo: Editora Gaia, 2002. 257 p.

DRUMMOND, G.M. Biodiversidade em Minas Gerais: um atlas para sua conservação. 2 ed. Belo Horizonte: Fundação Biodiversitas, 2005. 220 p.

GRADVOHL, A. Reciclando o lixo. Fortaleza: Editora Verdes Mares, 2001. 104p.

GRIPPI, S. Lixo, reciclagem e sua história: guia para as prefeituras brasileiras. Rio de Janeiro: Interciência, 2001.134 p.

HOLMGREN, K. E; HENNING, D. Comparison between material and energy recovery of municipal waste from an energy perspective: a study of two Swedish municipalities. Resources, Conservation and Recycling. Amsterdã, v. 43, n. 1, p. 51-73, dez. 2004. Disponível em: <http://www.sciencedirect. com/science> Acesso em: 17 dez. 2005.

IBGE, Instituto Brasileiro de Geografia e Estatística (ed.). Pesquisa Nacional de Saneamento Básico 2000. Rio de Janeiro: IBGE, 2002. Disponível em: $<$ http://www.ibge.gov.br/home/estatistica/populacao/ condicaodevida/pnsb/pnsb.pdf > . Acesso em: 23 mar. 2007.

IBGE. Cidades. Disponível em <http://www.ibge. gov.br/cidadesat/default.php $>$. Acesso em: 23 mar. 2007.

LEÃO, S.; BISHOP, I.; EVANS, D. Assessing the demand of solid waste disposal in urban region by urban dynamics modelling in a GIS environment. 
Resources, Conservation and Recycling. Amsterdã, v. 33, n. 4, p. 289-313, nov. 2001. Disponível em: $<$ http://www.sciencedirect.com/science $>$ Acesso em: 17 dez. 2005.

NEIVA, A. Reciclagem cresce no Brasil. Ecologia e Desenvolvimento, Rio de Janeiro, a. 11, n. 96, p. 18-19, set. 2001.

OLIVEIRA, L. B. Aproveitamento energético dos resíduos sólidos urbanos. Revista Gerenciamento Ambiental, a. 3, n. 15, p. 42-45, jul./ago. 2001.

RODRIGUES, A. M. Produção e consumo do e no espaço: problemática ambiental urbana. São Paulo: Hucitec, 1998. 239 p.

VILHENA, A. A coleta seletiva de lixo: uma proposta de programa de gestão integrada. 1996. 159 p. Dissertação (Mestrado em Ciências em Engenharia de Produção) - Programa de Pós-graduação em Engenharia, Universidade Federal do Rio de Janeiro, Rio de Janeiro, 1996.

VILHENA, A.; D’ALMEIDA, M. L. O. Processamento do lixo: segregação de materiais. In:

(coordenadores). Lixo municipal: manual de gerenciamento integrado. São Paulo: IPT/CEMPRE, 2000. p. 81-89. 